\title{
O papel do Estágio Curricular no desenvolvimento de projetos interdisciplinares por alunos do Ensino Médio Integrado à Formação Profissional em Informática
}

\author{
Ana Luísa de C. L. Duboc ${ }^{1}$, Robson Costa de Castro $^{2}$, Viviane S. R. Silva ${ }^{1}$ \\ ${ }^{1}$ Departamento de Computação - Colégio Pedro II - Campus Tijuca II - Rio de Janeiro - RJ - Brasil \\ ${ }^{2}$ Departamento de Física - Colégio Pedro II - Campus Tijuca II - Rio de Janeiro - RJ - Brasil \\ alduboc@gmail.com, prof.robinho@gmail.com, prof.vivianerodrig@gmail.com
}

\begin{abstract}
The objective of this research is to present the methodology practiced in the Compulsory Curricular Internship in Computer Science of Pedro II School, a federal public institution located in the State of Rio de Janeiro. his methodology focuses on the development of interdisciplinary projects, such as the creation of "Virtual Worlds" and "Computer Simulators"to assist TeachingLearning in different disciplines. It can be observed a greater motivation of the students, since all technical content learned is applied in the elaboration of pedagogical tools, contributing significantly to the advancement of the technology in the educational scope.
\end{abstract}

Resumo. O objetivo dessa pesquisa é apresentar a metodologia praticada no Estágio Curricular Obrigatório do Ensino Médio Integrado à formação profissional em Informática do Colégio Pedro II - campus tijuca II, instituição pública federal localizada no Estado do Rio de Janeiro. Tal metodologia tem como foco o desenvolvimento de projetos interdisciplinares, dos quais destacam-se a criação de "Mundos virtuais"e de "Simuladores Computacionais"para auxiliar o Ensino-Aprendizagem em diferentes disciplinas. Pode-se observar uma maior motivação dos alunos, pois todo conteúdo técnico aprendido é aplicado na elaboração de ferramentas pedagógicas, contribuindo significativamente para o avanço da tecnologia no âmbito educacional.

\section{Introdução}

O Ensino Público Brasileiro inserido dentro da estrutura capitalista moderna, adquire características próprias deste modo de produção. Isto é, em uma sociedade flexível, pautada no mercado de trabalho, a educação tem que cumprir com a formação dos jovens com a finalidade de ocupar futuras vagas neste sistema. Dessa forma, o Ensino Médio Integrado surge como uma preparação técnica para a cidadania e para a inserção da juventude no mercado de trabalho. Porém, é necessária uma análise para averiguar se a formação que estes alunos recebem cumpre realmente com este objetivo [Borges 2009].

O Colégio Pedro II tem sido responsável pela formação de alunos que, ao cursarem o Ensino Médio Integrado à formação profissional em Informática, agregam conhecimentos específicos, tais como: o raciocínio lógico para construção de algoritmos; a compreensão dos conceitos do paradigma orientado a objetos para o desenvolvimento de programas; os princípios básicos para a modelagem de sistemas de Banco de Dados 
e de sistemas web, e conhecimentos de Análise de Sistemas. Todo este aporte teórico tem o foco de ensinar técnicas de programação e análise de sistemas que permitirão a construção de ferramentas a serem utilizadas por diferentes ramos da sociedade, atuando no desenvolvimento, no teste e na manutenção de sistemas de informação. Desta maneira, estes jovens finalizam a Educação Básica agregando os conteúdos fundamentais descritos na LDB [MEC 2017] e o conhecimento computacional inicial necessário para o ingresso no mercado de trabalho.

A grande maioria dos nossos alunos chegam ao segundo ano do Ensino Médio Integrado com 16 anos e com uma base em lógica de programação, obtida no primeiro ano do Curso, no qual eles tiveram a oportunidade de exercitarem seus conhecimentos através do desenvolvimento de pequenas aplicações utilizando a linguagem C\#. É com essa base inicial que, a partir do segundo ano do curso, os alunos iniciam o cumprimento de 400 horas de Estágio Curricular Supervisionado obrigatório, obtidas através de cursos, palestras, projetos de Iniciação Científica, projetos internos ao colégio, ou atuando em uma das empresas ou instituições acadêmicas conveniadas ao Colégio. A partir de 2011, o Departamento de Ciência da Computação do campus Tijuca II tem sido responsável pela formação de alunos que implementou o estágio interno dentro da própria instituição com o objetivo de proporcionar aos discentes a experiência no desenvolvimento de projetos didáticos, educacionais ou empresariais.

Uma das frentes do Estágio interno é o desenvolvimento de ferramentas computacionais interdisciplinares que tem por objetivo auxiliar o ensino e aprendizagem de alunos e professores em diferentes disciplinas. O objetivo deste trabalho é descrever a metodologia praticada no desenvolvimento de tais projetos interdisciplinares, apresentando os principais projetos desenvolvidos e fazendo um relato das experiências vivenciadas e dos resultados obtidos. A metodologia descrita apresenta uma maneira de aproveitar a oportunidade de trazer inovação tecnológica para dentro das salas de aula, atendendo as demandas de professores e alunos do Ensino Fundamental e Médio, e ao mesmo tempo de ensinar e aprofundar os conhecimentos dos alunos durante sua formação técnica em programação e desenvolvimento de software, além de introduzí-los à prática da Pesquisa Científica.

O artigo está estruturado como se segue: Na seção 2 são discutidos alguns trabalhos correlacionados. Na seção 3 é apresentada a metodologia utilizada no desenvolvimento dos projetos. Na seção 4 são mostrados alguns produtos gerados no Estágio. Na seção 5 são apresentados os relatos das experiências e resultados obtidos e na seção 6 as conclusões, seguida de uma breve seção de agradecimento.

\section{Trabalhos Correlacionados}

Ao fazer um levantamento bibliográfico sobre a contextualização da Computação com as outras disciplinas da Educação Básica, encontramos diferentes abordagens que associam ferramentas tecnológicas ao ensino de disciplinas pertencentes ao núcleo básico. Entre elas estão o uso de dispositivos móveis e suas funcionalidades [Levay 2015, Freitas 2016], de softwares que se propõem a ensinar programação de forma intuitiva [Oro 2015], o uso da robótica [Guedes 2013], de simuladores computacionais no Ensino-Aprendizagem de Física e Química [Castro 2015, Silva 2016] ou ainda lidando com a realidade da resolução de problemas relacionados a áreas não exatas através do desenvolvimento de ferramentas 
VI Congresso Brasileiro de Informática na Educação (CBIE 2017)

Anais do XXIII Workshop de Informática na Escola (WIE 2017)

tecnológicas educacionais [da Silva Jacinto 2011].

Em [Silva 2016], por exemplo, é descrita a utilização do software de simulação PhET na prática pedagógica do Ensino de Quimíca. Os autores nortearam sua atividade em três momentos pedagógicos: problematização inicial, organização do conhecimento e aplicação do conhecimento. Foi concluido que a utilização da simulação virtual facilitou a visualização microscópica, em tempo real, da interação das partículas, auxiliando na assimilação e compreensão dos conceitos químicos envolvidos nos estados físicos da matéria.

Em [Freitas 2016] é desenvolvida uma proposta de utilização de dispositivo movéis no ensino de Artes. Todo o projeto foi implementado no estágio supervisionado em ensino de informática e foi aplicado a uma turma de $3^{\circ}$ ano do ensino médio. A metodologia foi norteada pelo uso do aplicativo Estúdio Stop Motion para se criar vídeos a partir da técnica de Stop Motion, que se baseia no posicionamento sequenciado de fotografias, com o objetivo de dar movimento às imagens. Os autores concluiram que a comunicação visual realizada através da técnica utilizada despertou nos alunos interesse na realização da atividade, fazendo com que eles absorvessem o conteúdo de forma mais dinâmica e interativa.

Já em [Levay 2015] foi relatada a utilização de jogos digitais em dispositivos móveis no processo de ensino-aprendizagem de Inglês, para alunos de 4 a 6 anos de idade, em uma escola de idiomas na cidade de Recife. Os autores concluiram que a partir do uso de jogos digitais houve a possibilidade de assimilação de vocabulário e pronúncia e de revisitação de palavras pelos aprendizes. A proposta se mostrou motivadora dentro do contexto da sala de aula uma vez que os alunos demonstraram grande interesse em participar das atividades.

Os trabalhos correlacionados acima mostram a importância do desenvolvimento de projetos que se preocupam com a interdisciplinaridade tanto na proposta de implementar noções básicas do pensamento computacional [Bordini 2016], como na utilização de ferramentas computacionais no ensino-aprendizagem de diferentes disciplinas, o que confirma a necessidade de se incentivar pesquisas com este foco.

\section{Metodologia}

Os alunos do Ensino Médio Integrado à formação profissional em Informática iniciam o estágio interno a partir do $2^{\circ}$ Ano do Curso. No início do ano letivo são apresentados aos alunos os projetos interdisciplinares já em andamento, além de outros projetos que possam vir a despertar o interesse dos discentes. Em média participam dos projetos 35 alunos por ano, sendo que ao final do ano letivo, os alunos devem entregar uma ferramenta pedagógica pronta para ser aplicada em sala de aula.

Cada projeto apresenta um limite de vagas por ano, em torno de 8 a 10 alunos. A distribuição dos alunos é feita baseada em dois critérios: o interesse do aluno pela temática da proposta e a média final obtida nas disciplinas técnicas de Informática no ano anterior. Dentro de cada projeto os alunos podem formar grupos de 2 a 3 alunos ou trabalhar de forma individual. São realizados encontros semanais de 4 horas no qual os alunos, supervisionados por um professor do Departamento de Computação, desenvolvem as ferramentas propostas. A seguir são apresentados os diferentes atores que participam 
VI Congresso Brasileiro de Informática na Educação (CBIE 2017)

Anais do XXIII Workshop de Informática na Escola (WIE 2017)

do estágio interno e suas atribuições, e em seguida as etapas do processo de desenvolvimento das ferramentas pedagógicas.

\subsection{Atores que compõem o estágio interno e suas atribuições}

- Supervisor: Professores da área de Ciência da Computação, designados para articular com os professores das diversas disciplinas oferecidas no Colégio, orientálos na elaboração de uma proposta para uma ferramenta computacional relacionada ao conteúdo de sua disciplina e também responsáveis pela orientação aos estagiários durante todo o período de desenvolvimento da ferramenta solicitada.

- Professor da disciplina: Regente da disciplina autora da proposta. Deve definir, juntamente com os alunos, o conteúdo a ser trabalhado e representado na ferramenta computacional e para qual ano escolar o conteúdo se destina. Como tarefa inicial, deve preparar uma espécie de story board sobre o conteúdo selecionado. Este docente atuará como consultor na fase de seleção do material teórico que será utilizado na construção da ferramenta tecnológica, e também será responsável por avaliar a ferramenta em cada fase de sua elaboração, desde a interface até os casos de teste, para garantir que esta foi desenvolvida corretamente.

- Estagiário: alunos do $2^{\circ}$ ano do Ensino Médio Integrado à formação profissional em Informática distribuídos em grupos de trabalho. Estão presentes semanalmente nas sessões de estágio. Têm a responsabilidade de estudar as linguagens e plataformas disponíveis associadas ao tema e experimentar implementações possíveis para realizar as tarefas acordadas a cada encontro. Quando da proximidade de finalização das horas de estágio, o aluno-estagiário deve estar ciente de que atuará como monitor durante a aplicação da ferramenta à turma alvo, juntamente ao professor da disciplina. Devem dispor de horas para participarem de feiras e eventos relacionados ao tema. E por fim, participarem do treinamento da turma de estagiários no ano seguinte aquele onde atuou, para que a continuidade dos projetos não seja prejudicada.

\subsection{Etapas do processo de desenvolvimento das ferramentas pedagógicas em cada projeto interdisciplinar}

- Etapa 1: Apresentação mais detalhada dos objetivos do projeto escolhido pelos alunos. Demonstração das ferramentas já produzidas até o momento. Definição das novas ferramentas a serem desenvolvidas.

- Etapa 2: Estudo dos conteúdos pedagógicos a serem trabalhados. Estudos das linguagens e plataformas computacionais a serem utilizadas. Cada projeto utiliza um arcabouço de ferramentas computacionais que não necessariamente já foram apresentadas aos alunos durante a sua formação profissional. Então é preciso um período de ambientação no qual os alunos devem adquirir os conhecimentos técnicos necessários.

- Etapa 3: Desenvolvimento da ferramenta pedagógica proposta. Durante esta etapa de desenvolvimento, produtos intermediários são gerados e avaliados pelos professores envolvidos no projeto.

- Etapa 4: Aplicação da ferramenta em uma turma pré-definida pelo professor orientador da disciplina.

- Etapa 5: Avaliação da ferramenta. Esta avaliação é realizada a partir da observação pelo professor do uso da ferramenta em sala de aula. O professor avalia, por 
exemplo, a facilidade de uso da ferramenta tanto por ele quanto pelos alunos, assim como a assimilação do conteúdo pelos alunos.

- Etapa 6: Atualização da Ferramenta. Após a avaliação, são efetuadas as modificações que foram solicitadas pelo professor da disciplina.

- As etapas 4, 5 e 6 se repetem até que a ferramenta seja considerada pronta para a prática pedagógica.

\section{Algumas das Ferramentas Pedagógicas geradas no Estágio}

A seguir são apresentados alguns dos projetos interdisciplinares que vêm sendo desenvolvidos no estágio interno.

\subsection{Mundos Virtuais}

Este projeto consiste no desenvolvimento de Mundos Virtuais para as mais diversas disciplinas do Ensino Fundamental e Médio, visando tornar o aprendizado dos alunos mais interativo e dinâmico. Na literatura encontramos muitos autores que relatam sobre Mundos Virtuais, desenvolvidos com fins didáticos [Leuson M. P. da Silva 2016, Voss 2013, Nunes 2016, Dantas 2014]. Mundos Virtuais são ambientes computacionais que simulam ambientes reais ou fictícios, e nos quais se é possível criar diferentes cenários, objetos e personagens com os quais o aluno pode interagir. O aluno é inserido em um mundo onde aplica e reforça as competências obtidas em sala de aula.

Todos os Mundos Virtuais desenvolvidos neste projeto,utlizando-se a ferramenta gratuita Unity 3D [Unity3D 2017], têm como objetivo facilitar o aprendizado e memorização dos conceitos, através de animações e perguntas contidas em diversos lugares do ambiente virtual criado. Até o momento foram finalizados três Mundos Virtuais: O primeiro, voltado para a disciplina de Desenho, cria uma "cidade virtual" na qual o aluno pode visitar diferentes estabelecimentos e aprender diversos conceitos da disciplina a partir das interações com os objetos de cada ambiente. Os outros dois, voltado para a disciplina de Biologia, representam os sistemas Reprodutor e Circulatório, os quais o aluno pode percorrer e aprender sobre cada parte que os compõem. A Figura 1, ilustra os Mundos Virtuais citados.

\subsection{Simuladores de Física}

Este projeto consiste no desenvolvimento de simuladores de Física para Desktop e dispositivos móveis. O objetivo é criar ferramentas computacionais que simulem graficamente os principais fenômenos físicos discutidos no Ensino Médio,aproximando os conteúdos apresentados em sala de aula do cotidiano dos alunos.

Alguns simuladores já desenvolvidos para Desktop são: Efeito Fotoelétrico, Movimentos Retilíneo Uniforme (MRU) e Retilíneo Uniformemente Variado (MRUV), Movimento de um Pêndulo, Associação de Resistores, Efeito Doppler e Colisões Elásticas e Inelásticas. Em Novembro de 2015 foi iniciada a migração desses simuladores para aplicativos para dispositivos móveis, dando origem ao aplicativo FísicaCP2-Tijuca, que já conta com quatro simuladores: MRU, MRUV, Pêndulo e Colisões. O uso de dispositivos móveis, em específico, como ferramenta pedagógica auxiliar, visa aumentar o interesse dos alunos pelas aulas de Física, visto que agora eles podem observam o fenômeno físico estudado de forma prática, gráfica e divertida diretamente no seu celular ou tablet. 
VI Congresso Brasileiro de Informática na Educação (CBIE 2017)

Anais do XXIII Workshop de Informática na Escola (WIE 2017)

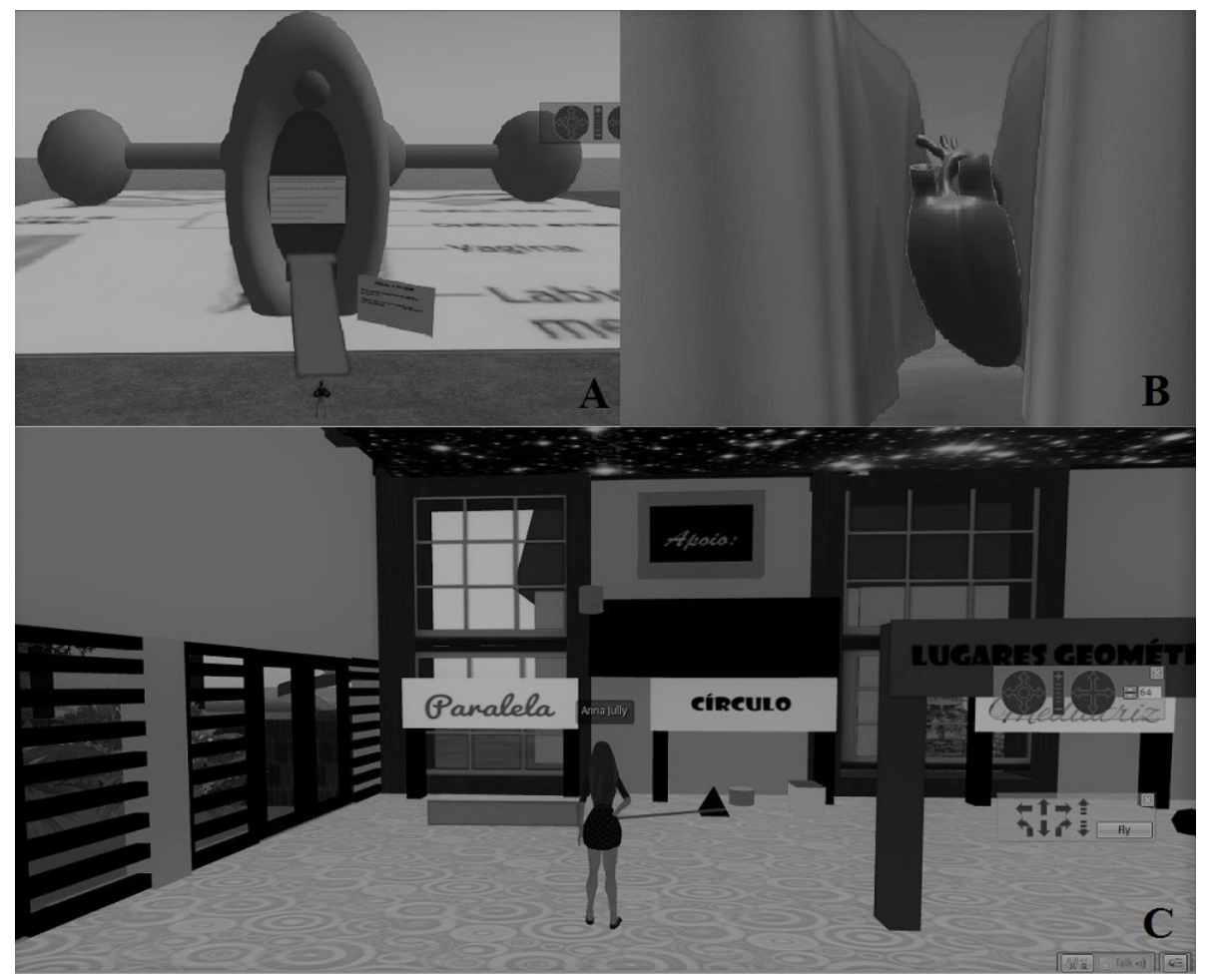

Figura 1. Mundos Virtuais: A - Sistema Reprodutor, B - Sistema Circulatório e C - Cidade Virtual.

Os softwares em versão Desktop foram desenvolvidos no Visual Studio 2012, versão Express [VisualStudio 2017] utilizando a linguagem C\#, enquanto o aplicativo foi implementado na ferramenta Android Studio [ANDROID_STUDIO 2017], utilizando-se a linguagem Java. Ambas as ferramentas são gratuitas para download e uso. A Figura 2 ilustra o aplicativo desenvolvido.

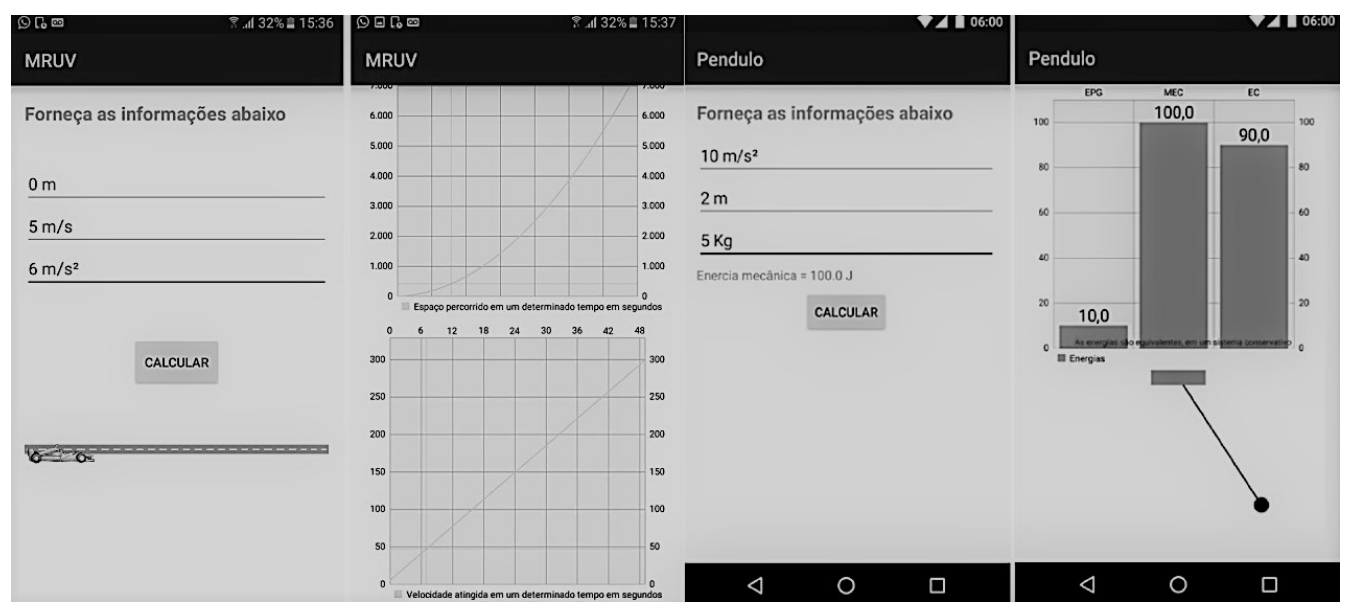

Figura 2. Aplicativo de Física analisando o Movimento Retilíneo Unimente Variado e o Movimento Pendular.

\subsection{Outra ferramentas pedagógicas criadas}

Além das ferramentas criadas nos projetos citados anteriormente, outras ferramentas com fins didáticos foram desenvolvidas pelos alunos do estágio. Entre elas estão um software 
VI Congresso Brasileiro de Informática na Educação (CBIE 2017)

Anais do XXIII Workshop de Informática na Escola (WIE 2017)

sobre Darwin, voltado para crianças, e que versa sobre a vida de Charles Darwin e a Teoria da Evolução; o desenvolvimento de uma calculadora matemática voltada exclusivamente para cálculos estátisticos, e uma outra voltada para transformações de bases binárias, decimais e hexadecimais; e o simulador de Química que visa facilitar os Cálculos Químicos.

\section{Relato das Experiências e Resultados Obtidos}

A experiência de se propor um Estágio interno para alunos do Ensino Médio Integrado à formação profissional em Informática é um tanto quanto desafiadora, não só pela idade com a qual os alunos iniciam o estágio como também pela responsabilidade de se proporcionar a eles uma experiência que se aproxime da realidade do mercado de trabalho.

Ao participarem de projetos interdisciplinares os alunos se vêem obrigados a lidar com clientes em potencial, no caso os professores das disciplinas e os alunos da turmas nos quais as ferramentas são aplicadas. Além disso, eles são incentivados a buscarem soluções inovadoras, muitas vezes difíceis, para conseguirem produzir a ferramenta proposta pelo projeto. Durante esse processo, os alunos constantemente se deparam com dificuldades técnicas e com a carência do conhecimento de programação necessário para dar continuidade ao projeto. Isso se dá por dois motivos: primeiro porque, muitas vezes, estão lidando com ferramentas computacionais ainda desconhecidas (como o UNITY e o ANDROID STUDIO, por exemplo) e segundo porque os projetos em geral possuem um nivel de complexidade grande, o que exige deles um conhecimento maior do que o de base. É interessante ver como que os alunos conseguem ultrapassar essas dificuldades técnicas através da prática da Pesquisa Científica, tanto por orientação do Supervisor quanto por iniciativa própria. Eles se organizam, pesquisam e encontram soluções para os problemas enfrentados, conseguindo alcançar os objetivos traçados.

Ao final do Estágio, percebe-se um enorme crescimento na maturidade dos alunos, como pessoas e como profissionais. Há uma mudança de comportamento na forma como eles passam a lidar com os professores, com os colegas, e com os estudos. Os alunos se tornam mais responsáveis e dedicados. Os alunos também se sentem orgulhosos por terem criado uma ferramenta pedagógica inovadora que será usada pelos outros alunos, ainda mais quando os projetos dos quais participaram são premiados em eventos externos ao Colégio Pedro II, como foi o caso dos projetos dos Simuladores de Física e dos Mundos Virtuais, que foram apresentados na Semana de Ensino, Pesquisa e Extensão (SEPEX 2016), realizada no CEFET/RJ, onde obtiveram a premiação do $2^{\circ}$ e $3^{\circ}$ lugar no segmento "Ciência da Computação", respectivamente. Esse sentimento de orgulho e os prêmios obtidos acabam por estimular novos alunos a participarem dos projetos.

Podemos observar que ao passar por todo este processo, muitos alunos confirmam a sua aptidão para Ciência da Computação e fazem a escolha por seguir a carreira nesta área. Em 2016, por exemplo, a maioria dos alunos que participaram dos projetos descritos acima, passaram para o curso de Ciência da Computação ou áreas afins em faculdades renomadas tais como UFRRJ, USP, UFF e CEFET/RJ.

Já do ponto de vista dos professores e alunos que usufruem das ferramentas pedagógicas criadas, tais ferramentas promovem a criação de um canal de comunicação digital entre a prática docente e os discentes, facilitando a aprendizagem dos contéudos apresentados em sala de aula. Além disso, como elas se aproximam de jogos e por algumas delas usarem dispositivos móveis, o que faz parte do cotidiano dos alunos, facilita o 
VI Congresso Brasileiro de Informática na Educação (CBIE 2017)

Anais do XXIII Workshop de Informática na Escola (WIE 2017)

engajamento dos mesmos e desperta um maior interesse pelos estudos.

Para nós professores, que participamos dos projetos como orientadores, é sempre um desafio encontrar alunos que aceitem a responsabilidade e abracem os projetos propostos durante um ano inteiro, principalmente quando temos que lidar com limitações técnicas, prazos, paralisações e outras condições adversas. Apesar das dificuldades, os projetos em andamento têm alcançado seus objetivos. Os mundos virtuais e os simuladores de Física criados foram aplicados em algumas poucas turmas para fins de teste e foram muito bem avaliados pelos alunos e professores. Enquanto este artigo esta sendo escrito, estamos em processo de liberação das ferramentas criadas para que estas possam ser usadas por todos os campi do Colégio e pelo público em geral. Após esta liberação, pretendemos fazer uma análise mais profunda da aplicação das ferramentas criadas em diferentes turmas e campi.

\section{Conclusões}

Neste trabalho podemos concluir que a metodologia praticada no Estágio Curricular Obrigatório do Ensino Médio Integrado à formação profissional em Informática do Colégio Pedro II - Campus Tijuca II, baseada no desenvolvimento de projetos interdisciplinares, vem contribuindo significativamente para o desenvolvimento técnico, profissional e pessoal dos discentes envolvidos no processo. Além disso, as atividades realizadas proporcionam a difusão da tecnologia na educação básica, por meio da criação e aplicação de ferramentas pedagógicas computacionais no ensino-aprendizagem de diferentes disciplinas do ensino fundamental e médio.

Acreditamos que o grande diferencial entre a metodologia praticada no Estágio do Colégio Pedro II e as metodologias aplicadas, por exemplo, nos trabalhos relacionados descritos, é que as ferramentas pedagógicas utilizadas neste projeto (simuladores de física e mundos virtuais, por exemplo), foram desenvolvidas pelos próprios alunos do Ensino Médio Integrado à formação profissional em Informática. Dessa forma o ganho acontece tanto para os alunos que têm a oportunidade de usar as novas ferramentas em sala de aula, como para os alunos que as desenvolveram.

Pretendemos dar continuidade aos projetos e contribuirmos cada vez mais para a formação dos nossos alunos do Ensino Médio Integrado, e para a inclusão cada vez maior da tecnologia no âmbito educacional.

\section{Agradecimentos}

Os autores agradecem aos professores do Colégio Pedro II, que participam ou participaram dos projetos, pela orientação dada aos alunos quanto ao conteúdo das ferramentas desenvolvidas nos projetos; à Pró-Reitoria de Pós-Graduação, Pesquisa, Extensão e Cultura (PROPGPEC) do Colégio Pedro II, pelo auxílio financeiro, na forma de Iniciação Científica, para alguns dos alunos do projeto de Simuladores de Física; e a todos os alunos do Ensino Médio Integrado que participaram ativamente nos projetos desenvolvidos durante o Estágio.

\section{Referências}

ANDROID_STUDIO (2017). Android studio - a ide oficial do android. https: / / developer. android.com/studio/index.html Último acesso em 13/03/2017. 
VI Congresso Brasileiro de Informática na Educação (CBIE 2017)

Anais do XXIII Workshop de Informática na Escola (WIE 2017)

Bordini, A., A. C. W. Y. d. C. M. d. C. C. S. F. L. A. M. e. R. R. (2016). Computação na educação básica no brasil: o estado da arte. Revista de Informática Teórica e Aplicada, 23(2):210-238.

Borges, A. C. (2009). O ensino integrado e a formação para o mercado de trabalho. In II Simpósio Estadual sobre a Formação de Professores de Sociologia na Universidade Estadual de Londrina, Escola Juventude, Londrina, PR, Brasil.

Castro, Robson Costa; Martins, M. C. S. J. F. R. (2015). Usando simulação computacional do efeito fotoelétrico no processo ensino-aprendizagem em física. In XXI Simpósio Nacional de Ensino de Física, Uberlândia, MG, Brasil. Editora Livraria da Física. p. 107.

da Silva Jacinto, Adriana, T. M. A. e. J. M. P. d. O. (2011). Aprendizagem baseada em problemas mal-estruturados: Programação e cidadania. In Anais do XVII Workshop de Informática na Escola (WIE 2011), Aracaju, SE, Brasil. pp. 1197-1206.

Dantas, Adriana D.;Maciel, L. D. C. T. L. I. N. A. R. (2014). Aplicando o sloodle como um ambiente de ensino e aprendizagem. In Anais dos Workshops do Congresso Brasileiro de Informática na Educação. Vol. 3. No. 1.

Freitas, Neliane Alves de; Marinho, W. T. S. M. P. N. d. N. O. N. B. (2016). Prática pedagógica com celular e stop-motion em interdisciplinaridade com artes. In Anais do XXI Workshop de Informática na Escola (WIE 2016), Uberlândia, MG, Brasil. pp. 953-957.

Guedes, Anibal Lopes, F. L. G. e. T. B. C. (2013). Perspectivas do uso da robótica educativa na educação infantil e no ensino fundamental. In Anais do XIX Workshop de Informática na Escola (WIE 2013), Campinas, SP, Brasil. pp. 410-414.

Leuson M. P. da Silva, Brendo C. Bonfim, R. C. S. J. B. d. S. W. L. M. C. I. M. B. P. M. J. (2016). Poogame: Um jogo sério para o ensino de programação orientada a objetos. In $24^{\circ}$ WEI - Workshop sobre Educação em Computação, Porto Alegre,RS, Brasil. CSBC 2016 - XXXVI Congresso da Sociedade Brasileira de Computação. pp. 2333-2242.

Levay, Paula Basto; Falcão, T. P. D. J. R. B. R. d. (2015). Uma experiência de uso de jogos digitais como ferramentas de apoio para aprendizagem de inglês por crianças. In Anais do XXI Workshop de Informática na Escola (WIE 2015), Maceió, AL, Brasil. pp. 207-216.

MEC (2017). Lei de diretrizes e bases da educação nacional(ldb). http: / / portal . mec.gov.br/seesp/arquivos/pdf/lei9394_ldbn1.pdf Último acesso em $30 / 06 / 2017$.

Nunes, F., H. F. Z. C. M. L. V. J. (2016). Utilização do mastery learning em sala de aula: uma abordagem integrada aos mundos virtuais. In $24^{\circ}$ WEI - Workshop sobre Educação em Computação. pp. 2442-2451.

Oro, Neuza terezinha; Pazinato, A. M. T. A. C. A. J. (2015). Olimpíada de programação de computadores para estudantes do ensino fundamental: A interdisciplinaridade por meio do software scratch. In Anais do Workshop de Informática na Escola (WEI 2015), Maceió, AL, Brasil. pp. 102-111. 
VI Congresso Brasileiro de Informática na Educação (CBIE 2017)

Anais do XXIII Workshop de Informática na Escola (WIE 2017)

Silva, Gerla Myrcea Lima da; Netto, J. F. d. M. S. R. H. d. (2016). A abordagem didática da simulação virtual no ensino da química: Um olhar para os novos paradigmas da educação. In Anais do XXII Workshop de Informática na Escola (WIE 2016), Uberlândia, MG, Brasil. pp. 339-348.

Unity3D (2017). Página oficial unity3d. https : / / unity3d.com/pt Último acesso em $14 / 03 / 2017$.

VisualStudio (2017). Página oficial do visual studio. https://www . visualstudio.com/pt-br/ Último acesso em 14/03/2017.

Voss, G., N. F. e. M. R. (2013). Proposta de um jogo sério para o ensino de redes de computadores no ambiente virtual 3d opensim. In Proceedings of the XI Brazilian Symposium on Games and Digital Entertainment-SBGames. pp. 37-40. 